\title{
CAMINHOS INOVADORES NA CIÊNCIA GEOGRÁFICA: A INSERÇÃO DA GEOGRAFIA BRASILEIRA NA ANÁLISE DOS SISTEMAS TERRESTRES1
}

Rosemary VIEIRA ${ }^{2}$

\begin{abstract}
RESUMO
O presente texto mostra parte do tema apresentado no II Congresso Brasileiro de Organização do Espaço e XIV Seminário do Programa de Pós-Graduação em Geografia da Universidade Estadual Paulista, Campus de Rio Claro. Trata-se de uma abordagem sobre a complexidade dos sistemas naturais e como a falta de entendimento de sua dinâmica e funcionamento potencializam as consequências das mudanças climáticas, manifestadas pelos eventos extremos e comprovadas majoritariamente pelos cientistas. Foram enfatizados os deslizamentos em grande escala na Região Serrana, em 2011, e os efeitos da erosão costeira na Região dos Lagos, no estado do Rio de Janeiro. Os dois eventos mostram que tanto a população como o poder público não manifestam real preocupação com a continuidade dos processos já ratificados pelos últimos relatórios do IPCC e por trabalho executados por um grande número de geógrafos. A análise das áreas de riscos e novas políticas públicas que necessitam ser implementadas pelos tomadores de decisão exigem cada vez mais a importante participação dos geógrafos, munidos hoje com grande arsenal teórico, metodológico e tecnológico.
\end{abstract}

Palavras-chave: Sistemas naturais. Eventos extremos. Deslizamentos. Erosão costeira. Riscos.

\section{INNOVATIVE PATHS IN GEOGRAPHIC SCIENCE: THE INSERTION OF GEOGRAPHY IN THE ANALYSIS OF TERRESTRIAL SYSTEMS}

\begin{abstract}
This work shows part of the theme presented at the II Brazilian Congress of Space Organization and XIV Seminar of the Geography Postgraduate Program, Paulista State University, Rio Claro Campus. It is an approach to the complexity of natural systems and how the lack of understanding of their dynamics and functioning can potentiate the consequences of climate change, manifested by extreme events and largely confirmed by scientists. Large-scale landslides in the Região Serrana in 2011, and the effects of coastal erosion in the Região dos

\footnotetext{
${ }^{1}$ Texto apresentado em palestra realizada no II Congresso Brasileiro de Organização do Espaço e XIV Seminário do Programa de Pós-Graduação (II CBOE), realizado na cidade de Rio Claro/SP, entre os dias 24 a 28 de março de 2019, intitulado "Soberania e Ciência no século XXI: a decolonialidade do saber como novo paradigma geografia?".

2 Professora do Departamento de Geografia e do PósGeo/UFF - Universidade Federal Fluminense.
} 
Lagos in the state of Rio de Janeiro were emphasized. Both events show that the population and the public authorities are not really concerned about the continuity of the processes already ratified by the latest IPCC reports, and by the work of a large number of geographers. The analysis of risk areas and new public policies that need to be implemented by decision makers increasingly require the important participation of geographers, armed today with a large theoretical, methodological and technological tools.

Keywords: Natural systems. Extreme events. Landslides. Coastal erosion. Risks.

\section{CAMINOS INNOVADORES EN LA CIENCIA GEOGRÁFICA: LA INSERCIÓN DE LA GEOGRAFÍA EN EL ANÁLISIS DE LOS SISTEMAS TERRESTRES}

\section{RESUMEN}

Este trabajo muestra parte del tema presentado en el II Congreso Brasileño de Organización Espacial y XIV Seminario del Programa de Posgrado en Geografía, Universidad Estatal Paulista, Campus Rio Claro. Es un acercamiento a la complejidad de los sistemas naturales y cómo la falta de comprensión de su dinámica y funcionamiento potencia las consecuencias del cambio climático, manifestado por eventos extremos y demostrado mayoritariamente por los científicos. Se destacan los deslizamientos de tierra a gran escala en la Região Serrana en 2011 y los efectos de la erosión costera en la Región dos Lagos en el estado de Río de Janeiro. Ambos eventos muestran que la población y las autoridades públicas no están realmente preocupadas por la continuidad de los procesos ya ratificados por los últimos informes del IPCC y por el trabajo de un gran número de geógrafos. El análisis de las áreas de riesgo y las nuevas políticas públicas que deben ser implementadas por los tomadores de decisiones requieren cada vez más la importante participación de los geógrafos, armados hoy con un gran arsenal teórico, metodológico y tecnológico.

Palabras-clave: Sistemas naturales. Eventos extremos. Deslizamientos. Erosión costera. Riesgos.

\section{INTRODUÇÃO}

Este trabalho é fruto da participação da mesa "Caminhos Inovadores na Ciência Geográfica: a Inserção da Geografia Brasileira”, durante o II Congresso Brasileiro de Organização do Espaço e XIV Seminário do Programa de PósGraduação (II CBOE), intitulado "Soberania e Ciência no século XXI: a Descolonialidade do Saber como Novo Paradigma da Geografia?”. O evento foi organizado pelo Programa de Pós-Graduação em Geografia da Universidade 
Estadual Paulista “Julio de Mesquita Filho", Campus de Rio Claro - SP, em março de 2019.

O título da palestra e do presente trabalho: "Caminhos Inovadores na Ciência Geográfica: a Inserção da Geografia na Análise dos Sistemas Terrestres” transmite a ideia de que é preciso conhecer mais os sistemas naturais, ver os sinais que eles estão nos dando há tempos. No evento foram abordados vários exemplos de desconsideração dos processos naturais, mas neste manuscrito são priorizados dois casos: as chuvas intensas na região serrana do Rio de Janeiro em 2011 e a erosão costeira no Estado do Rio de Janeiro, com recorte espacial para o município de Cabo Frio, na Região dos Lagos.

Foram abordadas questões referentes aos fenômenos operantes nos sistemas terrestres que mais e como nos impactam, no caso, o Brasil, além da inserção da Geografia nessa abordagem interdisciplinar. Essas questões estão inseridas no contexto de que as mudanças climáticas e ambientais não somente estão acontecendo, como também mudou de patamar, sendo agora o termo adotado "crise climática3, para descrever de forma mais precisa e enfática a atual crise ambiental em escala global.

Desde o evento em março foram publicados os Relatórios do IPCC sobre o impacto do uso do solo sobre o clima, em agosto, e sobre a situação da criosfera e dos mares, em setembro, o que foram incluídos nesse trabalho.

\section{SISTEMAS TERRESTRES}

Atualmente, um grande desafio científico é compreender o sistema terrestre, cujos processos operam independentemente da ação humana, mas que ao mesmo responde em diferentes escalas espaciais e temporais a influência cada vez mais incisiva da própria ação humana.

Sistemas terrestres constituem processos naturais e humanos que abarcam interações entre a atmosfera, oceanos, gelo, biogeoquímica e a humanidade. No entanto, a humanidade está perturbando todo o sistema, produzindo consequências tanto positivas como negativas (NOBRE et al., 2011),

3https://www.theguardian.com/environment/2019/may/17/why-the-guardian-is-changing-thelanguage-it-uses-about-the-environment?fbclid=IwAR1YisiusAq3JHOqm1glvwpU1MNg2tVo1zZ w99Eg-XmFz4uqcjIOqmznZc4 
talvez como resultado da ainda incipiente visão transdisciplinar das dinâmicas do planeta, da vida, da natureza e da civilização, que torna os sistemas extremamente complexos, como menciona Veiga (2019), limitando ainda o a ciência ao pensamento sistêmico não ampliando para o necessário conhecimento complexo.

Atualmente existem evidências robustas de que as atividades humanas influenciam os eventos extremos de temperatura e de precipitação. Cientistas têm identificado nos últimos anos eventos extremos que não poderiam acontecer sem a influência humana nas mudanças climáticas (HERRING et al., 2018). Essas evidências têm um papel-chave na tomada de consciência pública sobre as mudanças climáticas e a elaboração de políticas para a mitigação e adaptação (BELLPRAT et al., 2019)

A ocorrência de eventos meteorológicos severos chama a atenção do público e dos governos pelo fato de serem a principal causa de desastres naturais. Estas condições adversas do tempo normalmente estão diretamente associadas a transtornos que afetam a sociedade (LIMA, 2010). Desde o início do século foram vários os eventos catastróficos que impactaram com mais frequência e intensidade o Brasil. Furacão Catarina (2004), secas na Amazônia (2005, 2010 e 2016), inundações no Vale do Itajaí (2008; 2011), deslizamentos de encostas em Angra dos Reis e Rio de Janeiro (2010), deslizamentos e inundações na região Serrana do Rio de Janeiro (2011), deslizamentos e inundações na cidade do Rio de Janeiro (2016, 2019), além do avanço da erosão em grande parte da zona costeira brasileira. Paradoxalmente, ditos desastres são previsíveis e recorrentes nos mesmos locais e estações do ano (GÜNTHER et al., 2017).

\section{REGIÃO SERRANA DO RIO DE JANEIRO}

De acordo com as Nações Unidas, uma das mais impressionantes catástrofes climáticas no mundo se deu na Região Serrana do Rio de Janeiro, em 11 e 12 de janeiro de 2011 (Figura 1). A Região Serrana foi devastada bruscamente por chuvas intensas, com deslizamentos nas encostas, gerando perdas de centenas de pessoas, com danos ambientais, sociais e econômicos (SILVA JUNIOR; VIEIRA, 2013). 
Não desconsiderando a intensidade do evento meteorológico, as consequências poderiam ser menos calamitosas se o ambiente físico da Região Serrana fosse melhor entendido e considerado, apesar da grande complexidade que envolve os sistemas naturais. Em especial, porque o fator antrópico pode potencializar esses eventos.

Figura 1: Cidade de Nova Friburgo dentro da Região Serrana do Rio de Janeiro

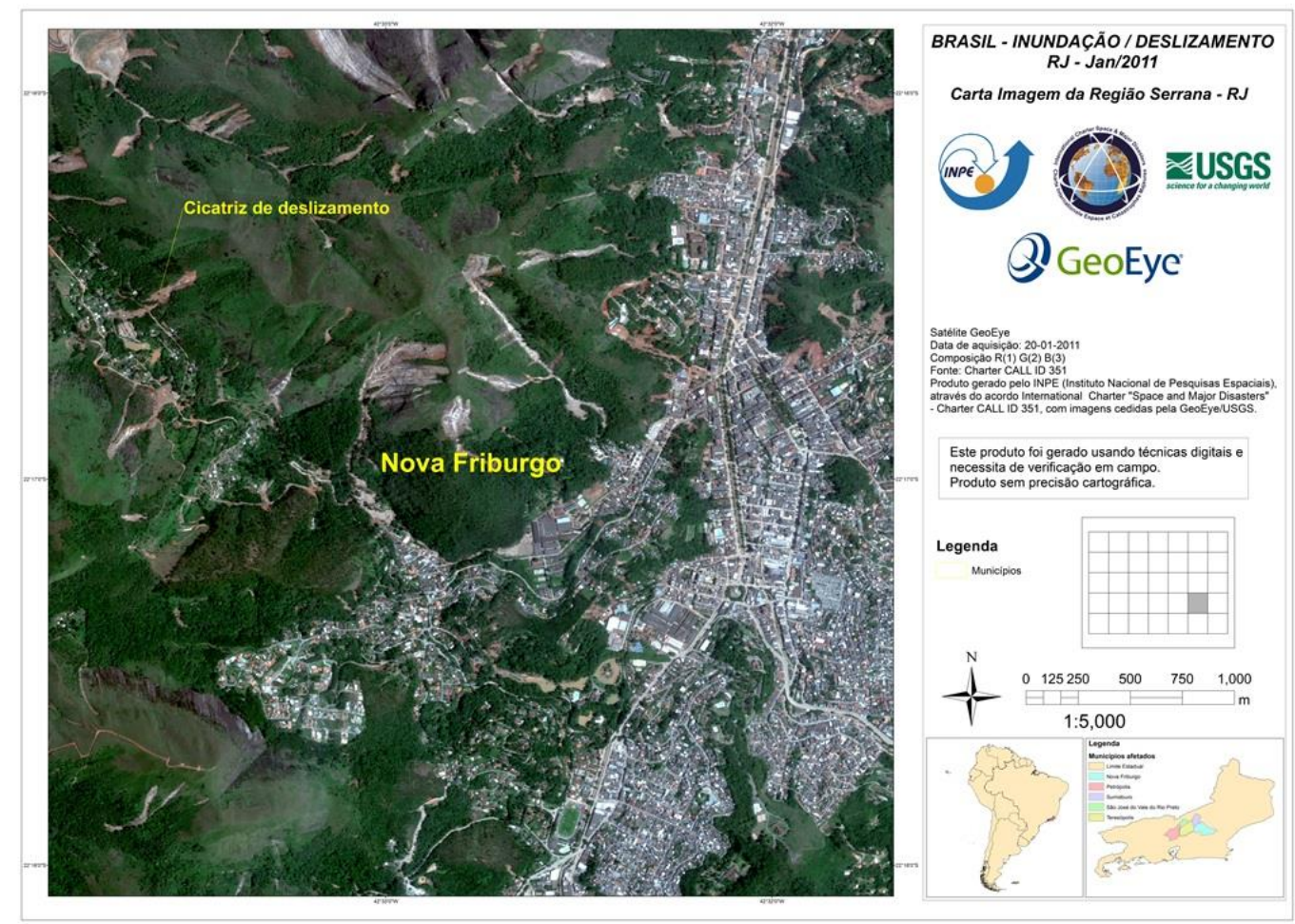

Fonte: INPE (2011).

Segundo os trabalhos de Santos (2004, 2008, 2012), as ações sobre os terrenos naturais interferem na natureza geológica, que têm história, leis e processos dinâmicos próprios. Esta natureza uma vez desconsiderada manifesta-se buscando, à sua forma, recompor-se dos desequilíbrios a que lhe foram impostos. Nesse contexto, a Serra do Mar, que é caracterizada por processos de erosão, deslizamentos de encostas, corridas de lamas e de detritos, os quais originaram novas áreas, algumas inclusive com topografia suave ao longo de milhões de anos, aponta naturalmente para a possibilidade de ocorrência de deslizamentos. A ocorrência de movimentos de massa na área 
relaciona-se, portanto, à conjunção de vários fatores, tais como: pluviosidade, declividade e forma das encostas, características geológicas e grau e tipo de interferência humana. Para definir a maior ou menor probabilidade de ocorrência destes fenômenos, a pluviosidade e a declividade das encostas são fatores decisivos.

Atuam na Região Serrana distintos mecanismos climáticos, com a penetração de sistemas frontais do sul, massas tropicais marítimas de lestenordeste e correntes do interior de norte-noroeste. Fenômenos de grande escala, como a Zona de Convergência do Atlântico Sul (ZCAS), gera condições de particular instabilidade (NUNES et al., 2009).

A Região Serrana ainda alberga remanescentes de ecossistemas florestados, porém em estágios distintos de sucessão vegetal e estados de conservação. Nessas áreas ocorrem sérios problemas com respeito ao uso do solo e a ocupação desordenada das terras, com reflexos nos impactos dos deslizamentos e inundações (NETTO et al., 2012). Portanto, chuvas concentradas, encostas desprotegidas de vegetação, contato solo-rocha abrupto, descontinuidades litológicas e pedológicas, declividade das encostas são algumas das condições encontradas na Serra do Mar que podem acelerar os processos erosivos (CUNHA; GUERRA, 2006), que juntamente com o manejo não adequado podem intensificar a degradação (GUERRA et al., 2007).

Com o crescimento industrial ao longo do século XX, Nova Friburgo, uma das cidades da Região Serrana mais impactadas pelas chuvas de 2011, passou a atrair habitantes dos municípios vizinhos e irradiando desenvolvimento para toda a região do centro-norte fluminense (DUARTE, 2009). Por conseguinte, foi adotado por seus sucessivos dirigentes um processo de negação e desrespeito às leis e aos processos naturais, ou por desconhecimento, por descuido, ou por irresponsabilidade, rendendo-se à pressão econômica e imobiliária. Como consequência, ocupação descontrolada de encostas e fundo de vales (cortes, aterros, desmatamentos), uso inadequado do solo e assoreamento de rios.

$\mathrm{Na}$ semana que antecedeu ao desastre a Zona de Convergência do Atlântico Sul atuava sobre a Região Serrana e trouxe para a cidade de Nova Friburgo, em menos de seis horas, a precipitação necessária para ultrapassar o nível de inundação dos principais rios e o volume esperado para o mês de 
janeiro inteiro. Do dia 11 para o dia 12 de janeiro a precipitação teve seu maior pico às três horas da manhã, quando os movimentos de massa e as inundações devastaram a cidade (Figura 2). A força das chuvas foi o suficiente para alterar o curso dos rios, desestabilizar as vertentes e originar uma nova geografia (CARDOSO; VIEIRA, 2016).

Figura 2. Manchete do jornal A Voz da Serra, de Nova Friburgo após o desastre de $11 / 01 / 11$.

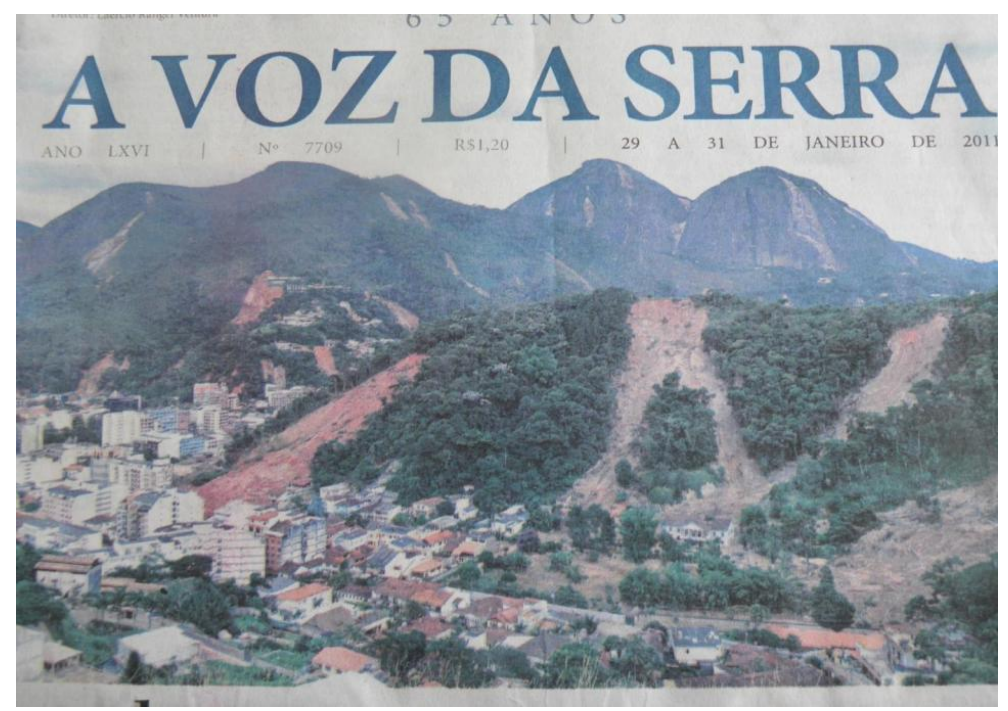

Para o Conselho Regional de Arquitetura e Urbanismo (CREA-RJ, 2011), o índice elevado de precipitação foi o componente deflagrador dos deslizamentos e do transbordamento dos rios, sendo os fatores predisponentes a geologia, geomorfologia e características morfométricas das bacias hidrográficas da região. Relacionando ditos fatores a antropização das bacias hidrográficas, essa tem sido causa agravante para a referida tragédia, uma vez que o desmatamento, a impermeabilização do solo e a ocupação desordenada em grande parte da bacia hidrográfica elevaram o escoamento superficial nas vertentes, gerando erosão. Esses processos agravaram os riscos de transbordamento hídrico e de deslizamentos das encostas, especialmente em vertentes com elevado grau de inclinação que é considerado inabitável. Informe do Instituto Brasileiro do Meio Ambiente e dos Recursos Naturais Renováveis (IBAMA, 2011) infere que cerca de 70 a $80 \%$ dos deslizamentos em Nova 
Friburgo teve as ações humanas como coadjuvantes, em seus mais distintos graus de intervenção (Figuras 3a-f).

Figura 2: Nova Friburgo. Deslizamentos e alagamento no centro da cidade em janeiro de 2011 (a-d); área de encostas ocupadas sem planejamento (e-f).
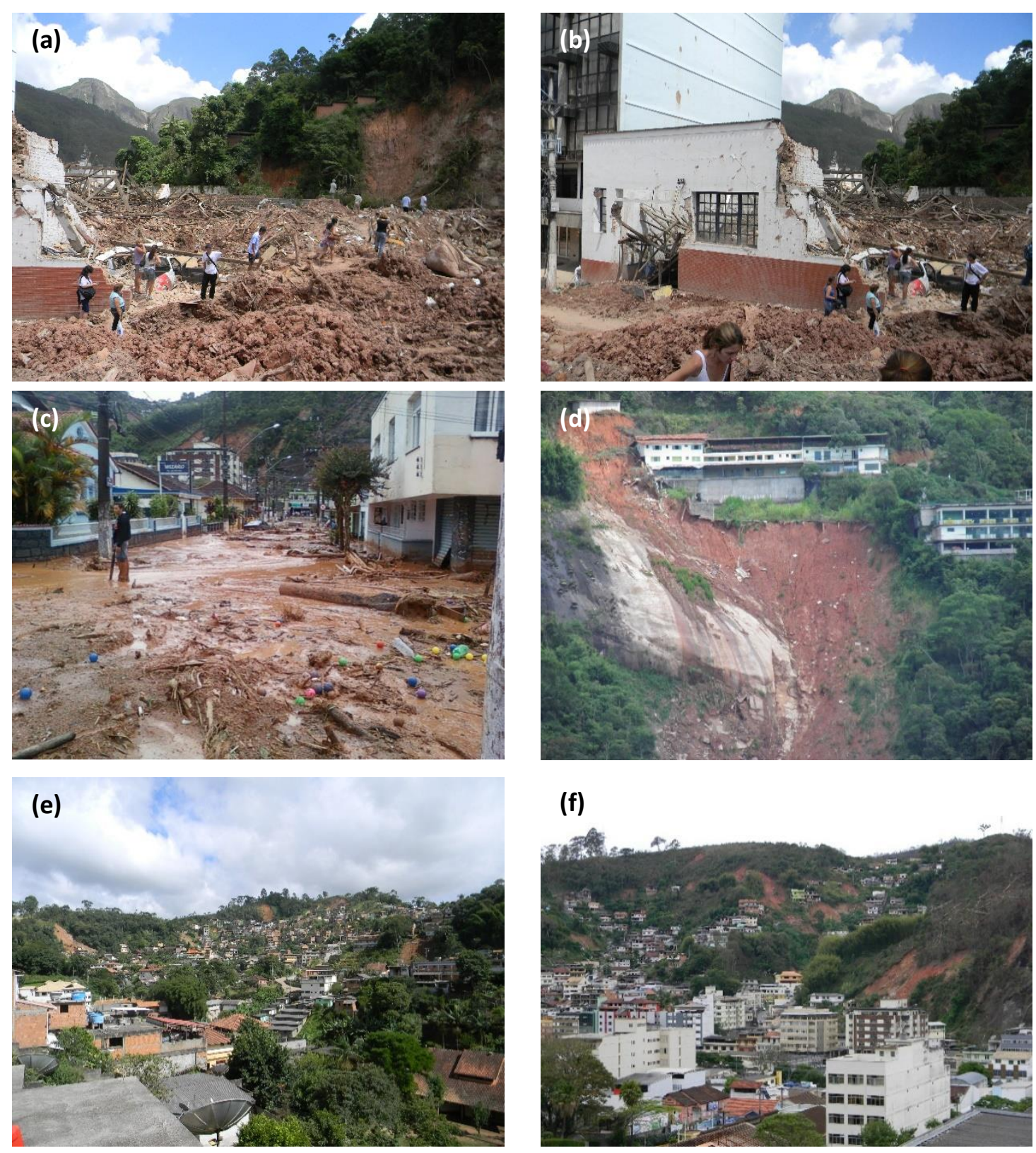

(f)

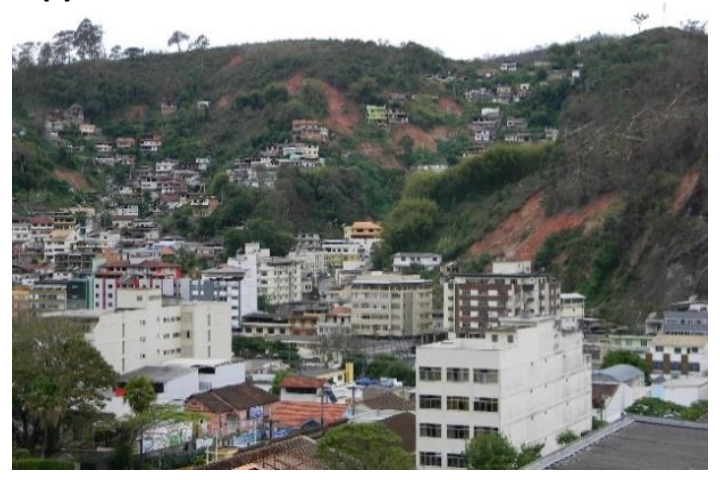

Fotos de Carlos Alberto Vieira e Rosemary Vieira.

\section{ZONA COSTEIRA DO RIO DE JANEIRO - REGIÃO DOS LAGOS}

Na zona costeira do estado do Rio de Janeiro a preocupação com os eventos de erosão, ressacas e ventos mais intensos passou a fazer parte da vida 
das pessoas que vivem junto ao mar. Nas últimas décadas a ocupação intensa e desordenada desconsiderou os riscos desse adensamento populacional próximo à praia. As sucessivas intervenções no ambiente costeiro, entre elas, a construção de estruturas, a maior pressão sobre os aquíferos costeiros, destruição de dunas e a retirada em grande escala das formações vegetais de restinga e manguezais diminuíram a capacidade de adaptação e suporte dessas áreas às alterações que estão em processo nos últimos anos, como o recuo da linha da costa, recuo da faixa de areia das praias e o aumento da intrusão salina nos corpos d'água costeiros. O ambiente costeiro, portanto, tornou-se mais vulnerável e sujeito a perdas ambientais e prejuízos econômicos, tendo em vista que 90\% da população do estado reside neste ambiente (IBGE, 2014).

Considerando o adensamento populacional em uma área que alberga distintos ambientes naturais sensíveis, como praias, dunas, restingas, mangues, planícies costeiras, deltas, localizados em cotas altimétricas de até 10 metros acima do nível médio do mar, torna-se evidente a ameaça sofrida por esses sistemas pelos impactos das mudanças climáticas.

Diversos estudos sobre a vulnerabilidade da zona costeira do estado do Rio de Janeiro diante dos possíveis impactos do aumento do nível relativo do mar e de eventos extremos vêm sendo produzidos por geógrafos, alertando sobre as tendências de tempestades mais intensas e o aumento do risco de erosão costeira (MUEHE et al., 2011; MUEHE; ROSMAN, 2011; BULHÕES et al., 2016).

A cidade de Cabo Frio, situada na Região dos Lagos, apresenta nos últimos cinco anos sinais de erosão costeira e recuo da linha de costa em alguns de seus pontos, como o $2^{\circ}$ Distrito de Tamoios (Figura 4). Até então, o caso mais evidente fora registrado e monitorado poucos quilômetros ao norte, na cidade de Rio das Ostras, onde a erosão costeira danificou estruturas e edificações (MUEHE et al., 2018). Estudos de Muehe et al. (2011) e de Bulhões et al. (2016) contrastam as duas áreas, sendo Barra de São João (município de Casimiro de Abreu) e Rio das Ostras, ao norte da foz do rio São João, com ampla exposição às ondas e à erosão, enquanto que de Barra de São João a Cabo de Búzios, ao sul da foz e onde se localiza o Distrito de Tamoios, há uma tendência de 
acumulação sedimentar. A região como um todo é geralmente impactada por ondas de tempestade que se distribuem principalmente entre os meses de abril e setembro.

Figura 3: Localização do Distrito de Tamoios, Cabo Frio.

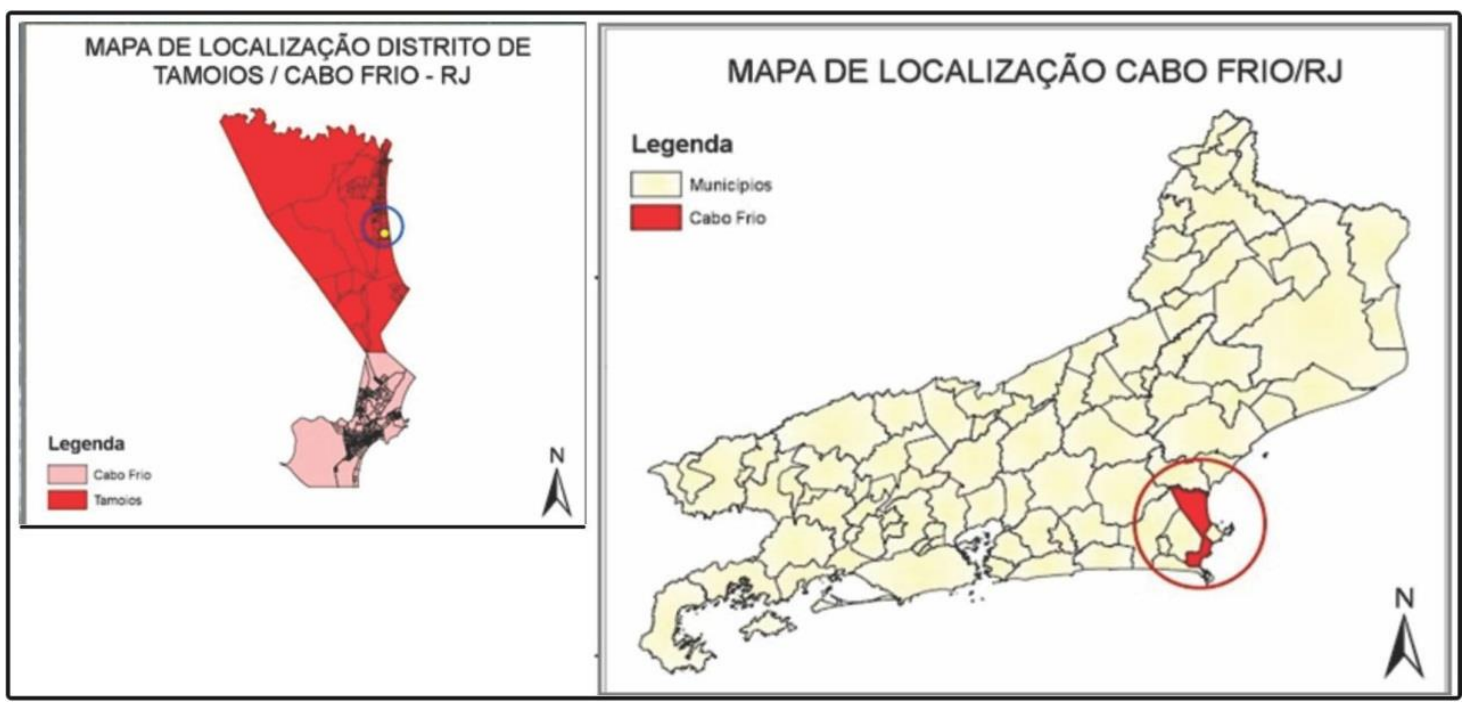

Adaptado de Vieira et al. (2019 - submetido).

Seguindo o exemplo da Região Serrana, a ocupação da Região dos Lagos se deu sem o conhecimento dos complexos sistemas oceanográficos e climáticos que atuam de forma diferenciada ao longo de toda costa do país, desprezando por completo os ecossistemas costeiros e seu papel fundamental na manutenção e, atualmente, na mitigação dos impactos ocasionados pelos eventos meteorológicos extremos. A ocupação e construções em grande escala próximas da orla impactaram profundamente essas áreas, alterando o balanço do estoque de areias das praias. A construção de cais e a implantação de estruturas portuárias altera o transporte de sedimentos, fazendo a areia acumular-se em um setor e faltar em outro (MÜEHE, 2006; 2013). Em outras palavras, faltou planejamento, o que hoje se tornou estratégico para lidar com os resultados da combinação dos eventos extremos e elevações do nível médio do mar: as inundações e a erosão costeira. Infelizmente, ainda são empregados como ações corretivas a colocação de muros e blocos de pedra, mutilando e descaracterizando por completo as praias, retirando a sua beleza cênica e desvalorizando os imóveis (Figuras 5-7). 
O Painel Brasileiro de Mudanças Climáticas, em seu relatório publicado em 2016, aponta que nos ambientes costeiros antropizados, os principais impactos associados são, entre outros: destruição e/ou comprometimento de propriedades e bens; redução de espaços habitáveis; contaminação dos aquíferos; maior vulnerabilidade de pessoas e bens; problemas com atividades econômicas; comprometimento da beleza cênica e perda do potencial turístico; problemas na aplicação da legislação ambiental vigente; alto custo de recuperação; perda da qualidade de vida. Boa parte desses impactos já são observados na Região dos Lagos.

Figura 4: Erosão costeira no Distrito de Tamoios, Cabo Frio, março de 2019.

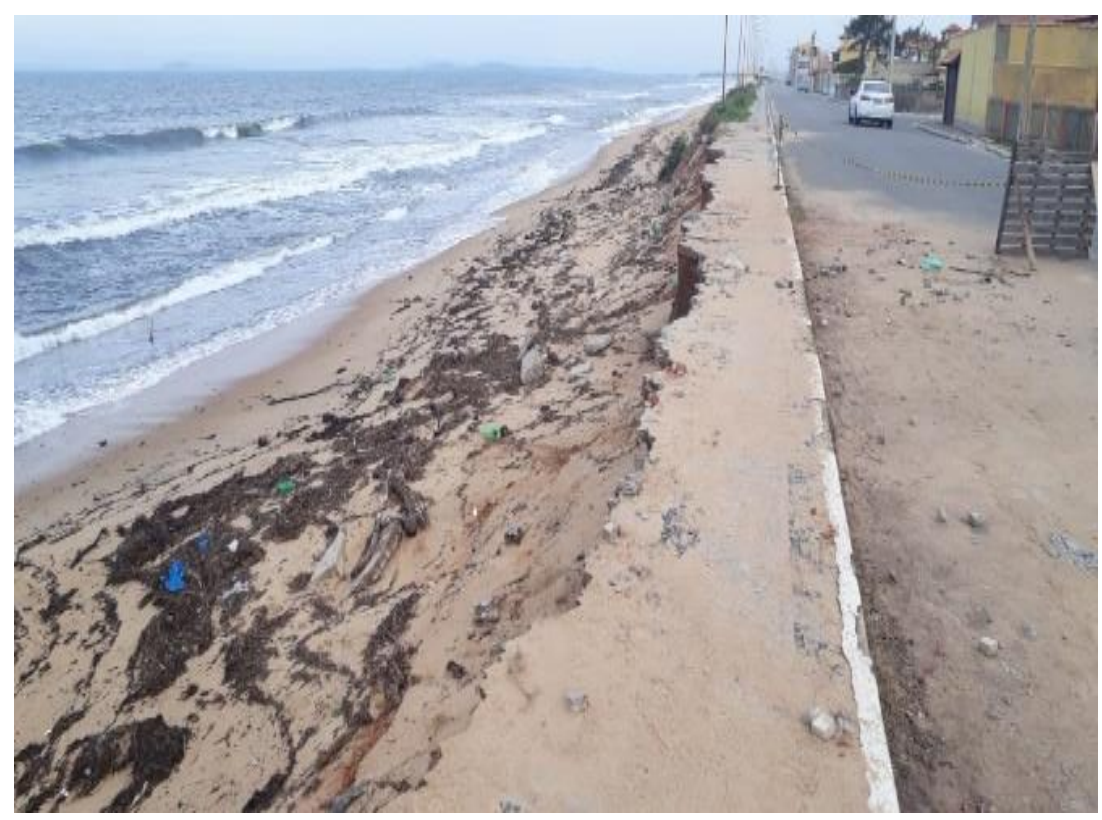

Foto de Rosemary Vieira. 
Figura 5: Obra de contenção da erosão costeira no Distrito de Tamoios, Cabo Frio.

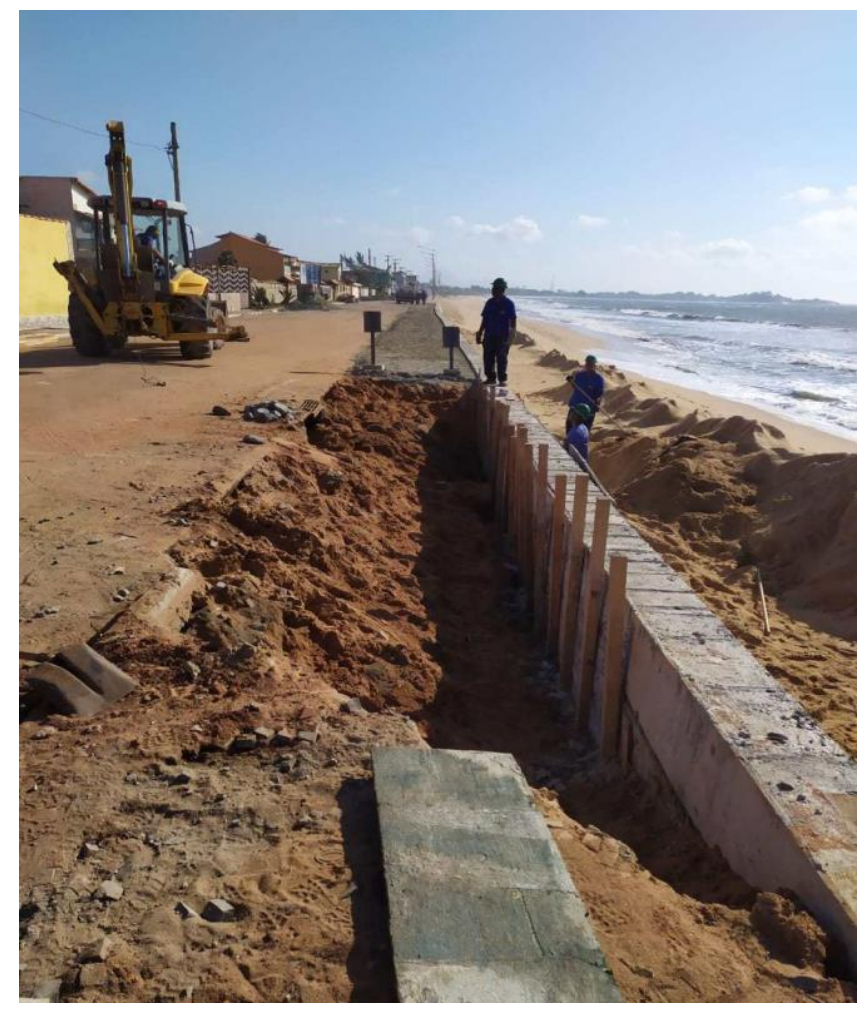

Fonte: Prefeitura Municipal de Cabo Frio.

Figura 6: Contenção da erosão costeira em Rio das Ostras (RJ), com a perda da areia e descaracterização da praia.

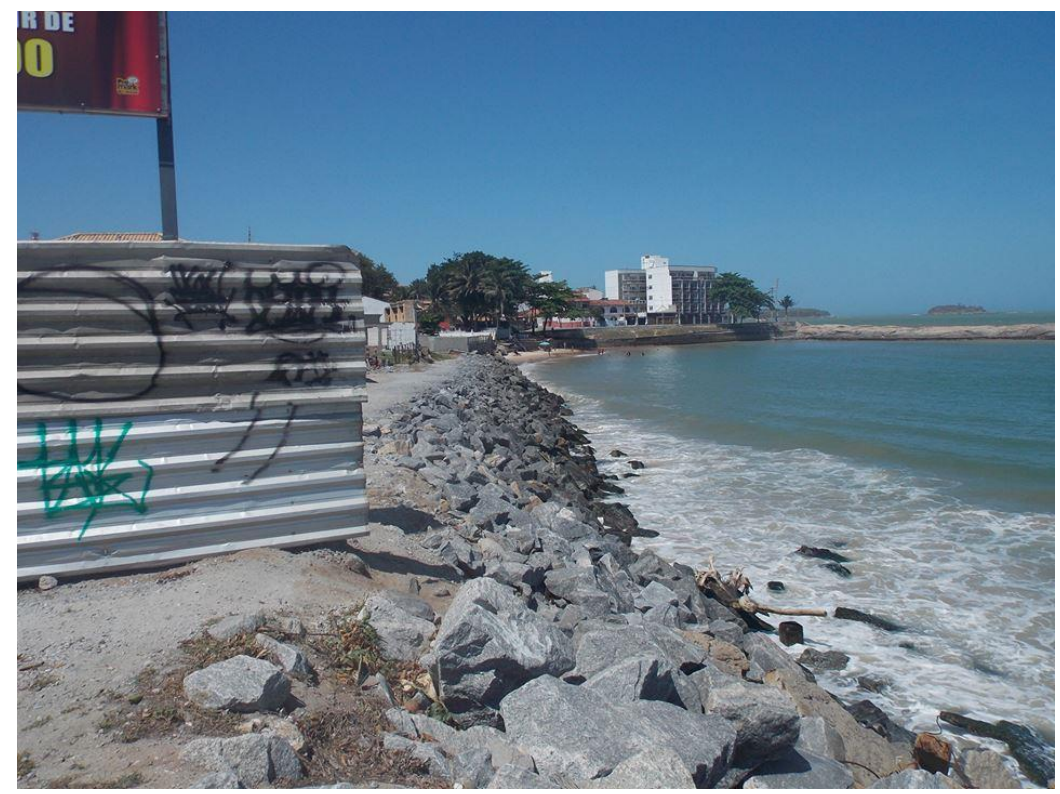

Foto de Rosemary Vieira. 


\section{A CIÊNCIA DOS DESASTRES NATURAIS}

As mudanças climáticas demandam urgência de políticas e ações que permitam desenvolver sociedades e cidades resilientes e reduzir os riscos e os próprios impactos dos eventos. Para isso, ciência e tecnologia, atuando em níveis acadêmicos inter e transdisciplinares, exercem papel fundamental, por exemplo, na investigação das causas dos desastres, na previsão meteorológica, na elaboração e construção de estruturas resilientes ou no controle de doenças e epidemias. Lidar com desastres naturais envolve lidar com a complexidade da dinâmica e inter-relações dos processos naturais, com as populações afetadas e como estas são afetadas, uma vez que muitos dos impactos apresentam distintos graus de intensidade.

Em um relatório apresentado em 2018 pela editora científica Elsevier, foram publicados em escala global, entre 2012 e 2016, vinte e sete mil artigos abordando estudos sobre os vários tipos de desastre, seus impactos, monitoramento do risco (prevenção) e o que fazer no pós-desastre (resposta). A distribuição desse número de publicações é majoritariamente influenciada pelo tamanho da economia dos países e, consequentemente, pelo desenvolvimento científico, sendo o continente asiático o que mais produz estudos: nove em cada dez artigos e com destaque para a China. Estados Unidos são o segundo maior produtor de artigos científicos, seguidos pelo Japão e Reino Unido. Por outro lado, países que sofrem pesadas perdas humanas e econômicas apresentam poucas publicações sobre o tema. O Brasil produz estudos e publicações relacionados principalmente aos desastres hidrometeorológicos: secas, enchentes, inundações e movimentos de massa. No entanto, a produção brasileira é baixa, ainda que seja referenciada pela produção científica de outros países.

De acordo com Zuquette (2018), a aquisição, processamento e análise de um conjunto de dados, em diferentes níveis de escala, são fundamentais para a previsibilidade dos eventos naturais e das estimativas de vulnerabilidade e risco, e que está diretamente ligado à atividade dos geógrafos: componentes do meio físico; atributos/propriedades dos componentes do meio físico; usos/alterações; deflagradores; inventários e elementos ambientais. Tais dados podem ser 
tratados e combinados sob distintas formas, com a produção de um amplo espectro de resultados, em função do tipo evento, dos métodos (quantitativos e qualitativos) e ferramentas empregadas. A revisão e atualização das cartas de risco já existentes, com a incorporação de novas áreas até então não consideradas igualmente requerem a disponibilidade de informações e de conhecimento técnico-científico provenientes de múltiplas áreas de conhecimento afins ao problema focalizado.

\section{RISCO, PERIGO E CRISE}

O termo risco é usado em diferentes áreas - geografia, geologia, engenharia, economia, administração pública, entre outras, como um cenário sujeito à ocorrência de um evento com determinada intensidade/magnitude que produzirá ao meio ambiente e à sociedade, efeitos acima de um dado limite suportável (ZUQUETTE, 2018).

Rebelo (2010) analisa risco como o somatório da importância do processo que pode acarretar situações de perigo, ou um processo potencialmente perigoso. Para haver risco é preciso que haja vulnerabilidade e, nesse sentido, os processos naturais só constituem risco se alguma coisa pode criar problemas ao homem ou às suas realizações, independente inclusive da sua presença. Os riscos naturais estão ligados direta ou indiretamente com a natureza, pois o homem está de alguma forma envolvido mediante a noção de vulnerabilidade, tornando-se muitas vezes o responsável pelo aumento da violência de sua manifestação ou expondo-se a ela. Perigo implica a proximidade do homem. A percepção do perigo é tão fundamental quanto à do risco, já que não há muito tempo de separar o perigo da crise. A crise é o terceiro momento temporal que se segue ao risco e ao perigo, quando as tentativas de defesa estabelecidas na percepção do perigo se tornam inoperantes, além das possibilidades de controle por parte do homem.

No caso dos diversos fatores de risco para a Região Serrana e, em especial, a cidade de Nova Friburgo, poderiam ser mencionados: (a) ocupação indevida das áreas ribeirinhas e encostas; (b) conivência/omissão do poder público na ocupação de áreas de risco; (c) mapeamento incipiente de áreas de 
inundação e de movimentos de massa; (d) ausência de planejamento integrado dos sistemas de drenagem urbana, com enfoque na bacia hidrográfica.

Pela combinação de fatores ligados ao relevo, como a inclinação das encostas, e aos elevados índices de precipitação na Região Serrana existe a susceptibilidade natural das encostas aos movimentos de massa. Se as chuvas caem em maior quantidade em períodos mais curtos e se as encostas estão desmatadas e/ou ocupadas, a água continua a buscar os seus caminhos naturais, ainda que ao longo desses caminhos existam agora edificações.

Por outro lado, a repetição das inundações ao longo dos anos deveria já ter produzido a rotina da prevenção e da mitigação das consequências da crise. Porém, isso não acontece. O próprio CREA declarou sobre o desastre em 2011, que: “...se as prefeituras cumprissem as leis brasileiras, $80 \%$ das vidas da região não seriam perdidas. Não é mais suportável ter a certeza de que, a cada verão, vidas serão perdidas..."

Para a zona costeira da Região dos Lagos, e em especial, o Distrito de Tamoios (Cabo Frio) alguns dos principais fatores de risco seriam: (a) tendência histórica de ocupação da zona costeira; (b) forte concentração populacional resultante da construção da Ponte Rio-Niterói, inaugurada em 1974, da ampliação da região metropolitana do Rio de Janeiro e da exploração de petróleo na Bacia de Campos (CALVANTE, 2008); (c) destruição da vegetação de restinga, que constitui Área de Preservação Permanente (APP); (d) mineração de areia no rio São João e possível desassoreamento de sua desembocadura; (e) balanço sedimentar negativo decorrente de intervenções antrópicas (SOUZA, 2008); (f) ausência de planejamento e criação de condições para um crescimento controlado.

\section{IPCC}

Onde haja um novo registro de evento climático extremo, tais como precipitações intensas ou grandes ressacas, é natural questionar se a ocorrência de tais eventos é devida ou não às mudanças climáticas. O relatório do IPCC Painel Intergovernamental sobre Mudanças Climáticas (2012): Managing the Risks of Extreme Events and Disasters to Advance Climate Change Adaptation 
projeta tendências de aumento da ocorrência e da intensidade de eventos climáticos extremos em todo o mundo, ainda que não se pudesse correlacionálos diretamente às mudanças climáticas, uma vez que eles são um aspecto integral da variabilidade climática.

O relatório: Global Warming of $1,5^{\circ}$ (2018) aponta que o aquecimento induzido pelo homem alcançou em $2017,1^{\circ} \mathrm{C}$ (variação entre $0,8^{\circ} \mathrm{C}$ e $1,2^{\circ} \mathrm{C}$ ) acima dos níveis pré-industriais, com cerca de $0,2^{\circ} \mathrm{C}$ de aquecimento por década (variação entre $0,1^{\circ} \mathrm{C}$ e $0,3^{\circ} \mathrm{C}$ ). Desde 2000, o nível estimado de aquecimento induzido pelo homem tem sido igual ao nível de aquecimento observado pela contribuição da atividade vulcânica e atividade solar.

O Relatório Climate Change and Land (2019) aponta que os eventos extremos ocorrem em um amplo espectro de escalas espaciais e temporais e podem incluir eventos relativamente curtos (e.g. tempestades extremas) ou a combinação ou a acumulação de eventos não-extremos (e.g. chuvas moderadas em uma zona saturada produzindo picos de inundação e/ou deslizamentos). Processos combinatórios referem-se a eventos compostos e são resultados da natureza e do número de variáveis físicas, da terra, de agentes biológicos como pestes e enfermidades, do espectro das escalas espacial e temporal e da intensidade da relação de dependência entre os processos (Figura 8).

Figura 7: Escalas espacial e temporal dos eventos extremos meteorológicos e climáticos e os sistemas biológicos por eles impactados (cinza).

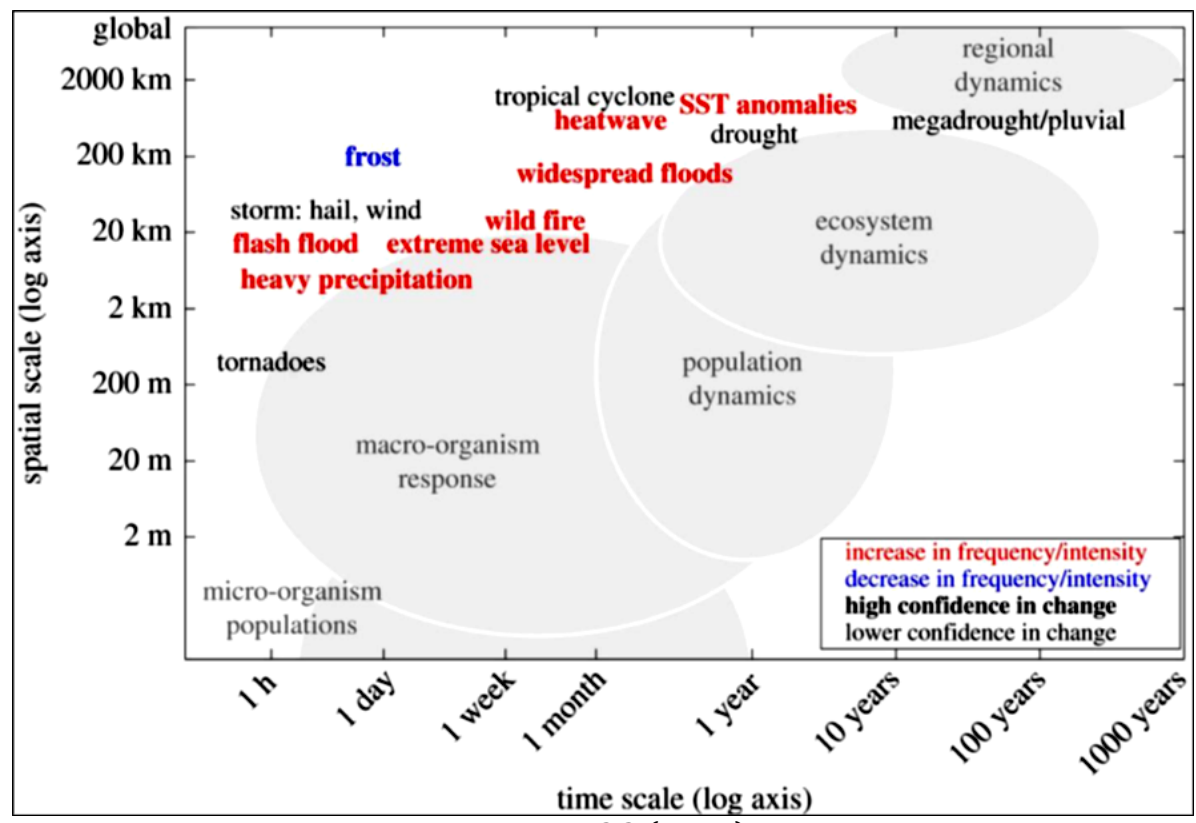

Fonte: IPCC (2019). 
Segundo o mais recente relatório: The Ocean and Cryosphere in a Changing Climate (2019), o nível médio global do mar está aumentando e de forma acelerada, sendo a soma das contribuições das geleiras e dos mantos de gelo a fonte dominante. É atribuída à forçante antropogênica a causa dominante dessa elevação. Os ecossistemas costeiros já estão impactados pela combinação da elevação do nível do mar, outras mudanças nos oceanos relacionadas ao clima e efeitos adversos das atividades humanas. Como consequência, ambientes costeiros perderam progressivamente a habilidade de adaptar-se às mudanças climáticas e de prover os serviços ambientais, incluindo a atuação de barreiras protetoras contra a erosão.

A elevação do nível médio global do mar até o final do século será mais rápida em todos os cenários projetados, entre 0,43 m (o,29-0,59 m) e o,84 m (o,61-1.10 m), relativo ao período 1986-2005. O mar continuará se elevando por séculos e permanecerá elevado por milênios. As populações costeiras estarão expostas e vulneráveis a elevação do nível do mar e aos eventos extremos na ausência de políticas de mitigação e de adaptação aos impactos da erosão, inundação e salinização. O relatório alerta que a tomada de decisões referentes às ações de mitigação e de adaptação deveria ser feita imediatamente.

Em pesquisa da Datafolha, publicada na Folha de São Paulo, em 28/07/2019, 85\% dos brasileiros acreditam que o planeta está se aquecendo e $72 \%$ afirmam que as atividades humanas contribuem para o fenômeno. Os percentuais caíram em relação à pesquisa de 21/04/2010, em que mais de 90\% dos brasileiros aceitavam que o aquecimento seja real e, para $75 \%$ dos entrevistados, as atividades humanas contribuam "muito" para as mudanças climáticas. O ceticismo/negacionismo climático, como é conhecida a corrente de pensamento que nega a existência do aquecimento global ou, pelo menos, o papel do homem nesse fenômeno, foi refutado em ambas as pesquisas no Brasil.

Os cientistas climáticos apontam os locais onde os impactos das variabilidades e das mudanças climáticas são mais evidentes ou onde a ocorrência de eventos extremos é mais provável, sendo sugeridas inclusive ações mitigadoras e de adaptação a serem adotadas pelo poder público. Paradoxalmente, existem ainda muitos obstáculos para tratar dos impactos das 
mudanças climáticas efetivamente, pelo menos em nosso país, devido ao pensamento muito comum entre as pessoas: "o que não vemos não nos assusta", apesar da aceitação das mudanças climáticas. Ainda que imagens em tempo real mostrem a ação dos fenômenos naturais em várias partes do mundo e também no Brasil, estas parecem despertar reações mais reativas do que preventivas nas pessoas, que ainda as veem de forma abstrata e distante, e nas autoridades que insistem em ignorar ou negá-las pela ausência de políticas públicas.

No Brasil existe uma grande discrepância entre os dados e alertas dos cientistas e iniciativas e ações concretas acerca do aumento da frequência e da magnitude dos eventos que afetam direta e indiretamente a população. A percepção do risco, ou seja, o senso que o indivíduo/sociedade apresenta frente ao risco potencial depende, entre outros, da condição social e econômica e da capacidade de julgamento (ZUQUETTE, 2018). Por mais que a população tenha as experiências com os problemas, muitas delas com perdas diretas, o grau de entendimento acerca da gravidade dos problemas ainda é incipiente.

Spence et al. (2011) demonstram que a falta de preocupação quanto a ocupação de áreas vulneráveis, tanto por parte da população como do poder público, está associada a percepção desses eventos como geograficamente longínquos e em uma escala de tempo futura. Portanto, uma das razões pelas quais as pessoas não tomam iniciativas e não pressionam o poder púbico para efetivação de ações mitigadoras quanto às consequências das mudanças climáticas e de eventos extremos seria a falta de experiências diretas de seus potenciais impactos. Mesmo passando por experiências, como os eventos hidrometeorológicos, a "cultura do esquecimento" parece dominar pouco tempo depois do evento. Portanto, a confusão pública sobre os temas científicos junto a desinformação e manipulação das informações contribui para a susceptibilidade da aplicação do viés pessoal e de grupos na interpretação dos eventos, mesmo diante de fatos concretos e documentados (PETERSEN et al., 2019), como os Relatórios do IPCC.

Malhi (2017) discorre sobre quatro linhas de pensamento sobre o tema, inclusive sustentadas pelo meio científico e pelo poder público, o que poderia explicar parte desse conflito: (a) a suposição de que o conhecimento das influências que o processo civilizador exerce sobre a dinâmica dos sistemas 
naturais permitirá gestão mais informada e racional dos problemas, mediante novos modos de governança; (b) aposta de que o crescimento econômico não seja acompanhado do uso indiscriminado dos recursos naturais e de impactos ambientais; (c) por outro lado, frente a provável ruptura dos sistemas naturais, só é admitida a possibilidade da humanidade abandonar o atual processo civilizatório; (d) por fim, a visão pragmática que visa a restauração das funções dos ecossistemas mais do que a necessidade de imensas reservas para a preservação das espécies naturais.

Em outras partes do mundo empresas e governos já trabalham e se organizam a partir de cenários elaborados cientificamente, objetivando preparar-se para um planeta em alteração, ou seja, adaptação. Cenários não são previsões: as previsões tendem a presumir que o futuro será uma continuação do presente; cenários são múltiplas versões do futuro. Imaginar um cenário leva os tomadores de decisão a prepararem-se para eles (FUNK, 2014).

\section{PARA REFLETIR - O DESAFIO DO FUTURO}

Grande parte do território brasileiro, e particularmente a região Sudeste, é caracterizada por climas quentes e úmidos, o que resulta em acentuada ação de intemperismo químico e também físico sobre as rochas. As regiões serranas tropicais registram históricos pluviométricos críticos, cujo exemplo marcante foram os deslizamentos na Serra das Araras e na Serra de Caraguatatuba, em 1967. Portanto, eventos de instabilidade das encostas nas regiões serranas quentes e úmidas no país são uma constante, o que torna imprescindível evitar o caráter catastrófico dos deslizamentos e inundações, que infelizmente, se tornaram uma constante.

Para as regiões serranas e costeiras do Rio de Janeiro não há outra saída senão repensar e repensá-las sob dois aspectos primordiais: o técnico/científico e o político/sócio/econômico.

A diminuição da extensão das praias em setores da Região dos Lagos, a maior inclinação do seu perfil, além dos impactos já sofridos pelas construções e infraestrutura não inibiu o interesse imobiliário e a persistente ocupação e destruição dos cinturões de vegetação nativa. Em seu lugar, construção de 
calçadões e impermeabilização do solo com a implantação do asfalto, desconsiderando que grande parte dessas áreas são tidas como Áreas de Preservação Permanente (APP) (RESOLUÇÃO CONAMA nº 303/2002).

A paisagem antropizada, como os calçadões com quiosques e ciclovias, tende a ser mais valorizada pelos residentes e turistas em lugar do funcionamento natural dos habitats e espécies (VAN DER MEULEN et al., 2004), alterando a percepção do ambiente e dificultando assim a aceitação por parte dos visitantes e moradores da presença dos terrenos naturais e da vegetação. A revisão das políticas públicas exige análises e interações espaciais entre os riscos. Zonas de riscos são mapeáveis nas mais diversas escalas o que conduz o papel fundamental do geógrafo, que dispõe hoje de um amplo espectro de recursos tecnológicos e metodológicos. Novas ações exigem coragem, más também exigem profissionalismo, pois envolvem relações políticas e socioeconômicas muito complexas, além da necessidade urgente da execução de ações muito mais delicadas, como a remoção da população das áreas de risco e de perigo iminente, a criação de novas áreas de ocupação que não sejam de risco e políticas de limitação do crescimento populacional em áreas de risco.

A repetição das inundações e dos deslizamentos ao longo dos anos deveria trazer consigo a rotina da mitigação das consequências da crise. Por isso, entra em cena a questão educacional, pois é principalmente através dela que se alcança a sensibilização da população quanto à percepção do risco, primordial para que a crise não ocorra, e se ocorrer, que tenha o mínimo possível de consequências nefastas.

Tudo isso requer, a longo prazo, uma mudança também cultural, pois ao incorporarmos o termo "desastre natural", acabamos por naturalizar o problema e caímos no risco de entendê-lo apenas parcialmente. Na Região Serrana do Rio de Janeiro as tragédias têm história e as zonas costeiras estão criando as suas. 


\section{REFERÊNCIAS}

BELLPRAT, O., GUEMAS, V., DOBLAS-REYES, F., DONAT, M.G. Towards reliable extreme weather and climate event attribution. Nature Communications, 1732, 10 (1), p. 1-7, 2019.

BULHÕES, E., FERNANDEZ, G., OLIVEIRA FILHO, S.R., PEREIRA, T.G. Coastal impacts induced by storm waves between Cabo Frio and Búzios, Rio de Janeiro, Brazil. Journal of Coastal Research 75, p. 1047-1051, 2016.

CALVENTE, P.M. A Urbanização na Vila de Tamoios (Cabo Frio) e sua inserção na Região dos Lagos (RJ): caracterização, implicações e consequências físico-ambientais e culturais. Dissertação de Mestrado. PósGraduação em Arquitetura e Urbanismo da Universidade Federal Fluminense, Niterói, 2008.

CARDOSO, P.S., VIEIRA, R.O. Megadesastre de janeiro de 2011 na cidade de Nova Friburgo, Rio de Janeiro: aspectos históricos desde a colonização suíça e as condicionantes físicas. Investigaciones Geográficas - Chile, 52, p. 47-70, 2016.

CREA. Conselho Regional de Engenharia e Arquitetura. $3^{o}$ Relatório de Inspeção à Região Serrana do Estado do Rio de Janeiro.

Recuperadode: $<$ http://www.crea-rj.org.br/wpcontent/uploads/2012/05/30_relatorio_chuvas_96DPI.pdf >.

CUNHA, S.B., GUERRA, A.J.T. Degradação Ambiental. In: Guerra, A.J.T., Cunha, S.B. (orgs.). Geomorfologia e Meio Ambiente. Bertrand Brasil, Rio de Janeiro, p. 337-379). 2006.

DU, F.R.P. Nova Friburgo: Um estudo sobre Identidade Urbanística. Dissertação de Mestrado, Universidade de Brasília. Brasília, (DF), 2009. Recuperado de:<http://repositorio. unb.br/bitstream/10482/4128/2/2009_ FernandaReginaPereiraDuarte_capitulo_3.pdf $>$.

ELSEVIER. A Global Outlook on Disaster Science, 52 pp, 2018.

FUNK, M. Caiu do Céu: O Promissor Negócio do Aquecimento Global. Ed. Três Estrelas, São Paulo, 359 p. 2014.

GÜNTHER, W.M.R., CICCOTTI, L., RODRIGUES, A.C., BOSCOV, E.G. O desafio da avaliação da resiliência comunitária aos desastres: uso de indicadores. In: Günther, W.M.R., Ciccotti, L., Rodrigues, A.C. (orgs.), Desastres: múltiplas abordagens e desafios. Elsevier Ed., Rio de Janeiro, p. 33$51,2017$.

GUERRA, A.J.G., GONÇALVES, L.F.H., LOPES, B.M. Evolução históricogeográfica da ocupação desordenada e movimentos de massa no município de 
Petrópolis nas últimas décadas. Revista Brasileira de Geomorfologia, 8 (1), p. 35-43, 2007.

HERRING, S.C., CHRISTIDIS, N., HOELL, A., KOSSIN, J.P., SCHRECK III, C.J., STOTT, P.A. (eds.). Explaining extreme events of 2017 from a climate perspective. Special Supplement to the Bulletin of the American Meteorological Society, 99, 12, 2018.

IBAMA. Instituto Brasileiro do Meio Ambiente. Relatório da Tragédia em Nova Friburgo, 2011. Recuperado de: http://ibamanovafriburgo.blogspot.com. br/2011/o2/relatorio-da-tragedia-de-nova. html.

IBGE. Instituto Brasileiro de Geografia e Estatística. Perfil dos Municípios Brasileiros 2013, Ministério do Planejamento, Orçamento e Gestão Instituto Brasileiro de Geografia e Estatística - IBGE, Coordenação de População e Indicadores Sociais, Rio de Janeiro, 282 pp, 2014.

IPCC. Intergovernmental Panel on Climate Change. Managing the risks of extreme events and disasters to advance climate change adaptation. Special Report of the Intergovernamental of Climate Change. Cambridge University Press. 594 pp, 2012.

IPCC. Intergovernmental Panel on Climate Change. Global Warming of $1,5^{\circ} \mathrm{C}$. Special Report of the Intergovernamental of Climate Change. Cambridge University Press. 538 pp, 2018.

IPCC. Intergovernmental Panel on Climate Change. Climate Change and Land. Special Report of the Intergovernamental of Climate Change. Cambridge University Press. 1542 pp, 2019.

IPCC. Intergovernmental Panel on Climate Change. The Ocean and Criosphere in a Chnaging Climate. Special Report of the Intergovernamental of Climate Change. Cambridge University Press. 1170 pp, 2019.

LIMA, K.C. Episódios de Precipitação Intensa no Sudeste do Brasil e a Influência das Anomalias de Temperatura da Superfície do Mar e da Topografia. Tese de Doutorado em Meteorologia. INPE, São José dos Campos, 2010.

MALHI, Y. The Concept of the Antropocene. Annual Review of Environment and Resources, 42, p. 77-104, 2017.

MUEHE, D., FERNANDEZ, G.B., BULHÕES, E., AZEVEDO, I.F. Avaliação da vulnerabilidade física da orla costeira em nível local, tomando como exemplo o arco praial entre Rio das Ostras e o Cabo Búzios, RJ. Revista Brasileira de Geomorfologia 12 (2), p. 45-58, 2011.

MUEHE, D. (org.). Erosão e Progradação do Litoral Brasileiro. Ministério do Meio Ambiente, Brasília, D.F. 476 pp, 2006. 
MUEHE. D. Erosão costeira, mudança do clima e vulnerabilidade. In Guerra e Jorge, 2013. Processos Erosivos e Recuperação de Áreas Degradadas. Oficina de Textos, SP, p. 160-189, 2013.

MUEHE, D., ROSMAN, P.C.C. A Orla Costeira da Região Metropolitana do Rio de Janeiro: Impactos das Mudanças Climáticas sobre o Meio Físico. Relatório Megacidades, Vulnerabilidade e Mudanças Climáticas: Região Metropolitana de Rio de Janeiro. Projetos Megacidades, Vulnerabilidade e Mudanças Climáticas, Rio de Janeiro, p. 75-106, 2011.

MUEHE, D., LINS-DE-BARROS, F.M., BULHÕES, E.M.R., KLUMBOLIVEIRA, L., PINTO, N., SPERLE, M. Rio de Janeiro. In Muehe, D. (Org.) Panorama da Erosão Costeira no Brasil. Ministério do Meio Ambiente, Brasília, p. 478-577, 2018.

NETTO, A.L.C., AVELAR, A.S., SATO, A.M., DIAS, M.A., SCHLEE, M.B., NEGREIROS, A.B. Vulnerabilidade em geoecossistema montanhosos e desastres causados por deslizamentos na interface florestal-urbana: controles geológicos, geomorfológicos e geoecológicos. In Lacerda, W.A., Palmeira, E.M., Netto, A.L.C., Ehrlich, M. (orgs). Desastres Naturais. COPPE/UFRJ, Rio de Janeiro, p. 63-80, 2012.

NOBRE, C., BRASSEUR, G.P., SHAPIRO, M.A., LAHSEN, M., BRUNET, G., BUSALACCHI, A.J., HIBBARD, K., SEITZINGER, S., NOONE, K., OMETTO, J.P. Addressing the complexity of the earth system. American Meteorological Society, 91 (10), p. 1389-1396, 2010.

NUNES, L.H., VICENTE, A.K., CÂNDIDO, D.H. Clima da Região Sudeste do Brasil. In CAVALCANTI et al. (orgs). Tempo e Clima no Brasil. Oficina de Textos, São Paulo, p. 243-258, 2009.

PBMC. Painel Brasileiro de Mudanças Climáticas. Impacto, vulnerabilidade e adaptação das cidades costeiras brasileiras às mudanças climáticas. Relatório Especial do Painel Brasileiro de Mudanças Climáticas [Marengo, J.A., Scarano, F.R. (Eds.)]. PBMC, COPPE - UFRJ. Rio de Janeiro, Brasil. 184 p.

PETERSEN, A.M., VICENTS, E.M., WESTERLING, A.L. Discrepancy in scientific authority and media visibility of climate change scientists and contrarians. Nature Communication, 2019.

REBELO, F. Geografia Física e Riscos Naturais, Imprensa da Universidade de Coimbra, Coimbra, 215 pp, 2010.

SANTOS, A.R. A Grande Barreira da Serra do Mar. Nome da Rosa, São Paulo, $122 \mathrm{pp}, 2004$.

SANTOS, A.R. Diálogos Geológicos. Nome da Rosa, São Paulo. 182 pp, 2008. 
SANTOS, A.R. Carta geológica e carta de riscos: distinções no significado, na elaboração e no uso. (pp. 19-26). In Lacerda, W.A., Palmeira, E.M., Netto, A.L.C., Ehrlich, M. (orgs). Desastres Naturais. COPPE/UFRJ, Rio de Janeiro, 2012.

SILVA JUNIOR J.F., VIEIRA, R. Variabilidad interanual de las precipitaciones en la Región Serrana de Rio de Janeiro, en el periodo 1971-2010.

Investigaciones Geográficas - Chile, 45, p. 19-36, 2013.

SPENCE, A. POORTINGA, W., BUTLER, C., PIDGEON, N.F. Perceptions of climate change and willingness to save energy related to flood experience. Nature Climate Change. 2011.

SOUZA, C.R.G. Erosão costeira e os desafios da gestão costeira no Brasil. Journal of Integrated Coastal Zone Management, 9 (1), p. 17-37, 2009.

VEIGA, J.E. O Antropoceno e a Ciência do Sistema Terra. $1^{\circ}$ edição, São Paulo, Ed. 34, 192 pp, 2019.

VIEIRA, R., CHAMBERLAIN, I.M.M., MONTEZUMA, R.C.M. Capacidade de carga física e qualidade recreacional das praias do setor sul do Distrito de Tamoios, Cabo Frio, RJ. Anais do Uso Público em Unidades de Conservação.

ZUQUETTE, L.V. Riscos, desastres e eventos naturais perigosos: aspectos conceituais na análise e estimativa de riscos. $1^{\circ}$ edição, Rio de Janeiro, Elsevier, 290 pp. 2018.

Recebido em abril de 2019

Aceito em maio de 2019 